J. Gen. Appl. Microbiol.

Vol. 9, No. 3, 1963.

\title{
CARBON DIOXIDE FIXATION IN GERMINATING CONIDIOSPORES OF ASPERGILLUS NIGER
}

\author{
TOMOMICHI YANAGITA \\ Institute of Applied Microbiology, University \\ of Tokyo, Tokyo \\ Received July 20, 1693
}

Conidiospores of Aspergillus niger strain 1617 require the presence in the medium of some amino acids, guanine, glucose and inorganic salts for their complete germination(1). Although the germination can take place without positive addition of carbon dioxide to the medium, it has also been found to be one of the essential factors for the initiation of germination (1, 2). When $\mathrm{CO}_{2}$ was eliminated from the environment, even the swelling of the conidia failed to occur in the germination medium. The optimum concentration of gaseous $\mathrm{CO}_{2}$ for germination of the conidia has been estimated to be about $0.1 \%$.

These observations have led us to investigate the heterotrophic fixation of $\mathrm{CO}_{2}$ in the germinating conidia of this fungus. Using ${ }^{14} \mathrm{CO}_{2}$ as tracer, the pattern of ${ }^{14} \mathrm{C}$-incorporation into conidial materials was analyzed.

\section{MATERIALS AND METHODS}

Preparation and cultivation of conidia. A dry sample of conidia of Aspergillus niger strain 1617 was prepared by the method of YANAGITA and YAMAGishi (3). For germination experiments, conidia were washed thoroughly with water and suspended in a germination medium (4) to give a final concentration of not more than $4.5 \mathrm{mg}$ per $10 \mathrm{ml}$. The germination medium contained DL-alanine, L-proline, guanine, glucose and phosphates (see foot note in Table 1). The culture was incubated in a water bath at $30^{\circ}$ with continuous shaking.

Vessels used for isotope experiments. The vessels employed for the labeling of conidia were, unless otherwise specified, Warburg-flasks fitted with rubber stoppers or an apparatus specially designed for the sampling from a closed vessel, which was a modification of that of Yanagita and Nishi (5). The assembly of the apparatus is illustrated in Fig. 1.

The medium was placed in a main flask, and an inoculum suspension and isotope solution were put separately into the two side arms. The entire reaction vessel was dipped into a water bath and the contents in the side arms were poured into the medium, then the culture was started by shaking. Aliquots of the culture were taken in the following way without opening the upper junction of the flask ${ }^{2}$.

1 Supported in part by a grant from the Ministry of Education.

2 This apparatus was designed to make possible the exchange of air in the main flask with other gas introduced through opening $a$. 


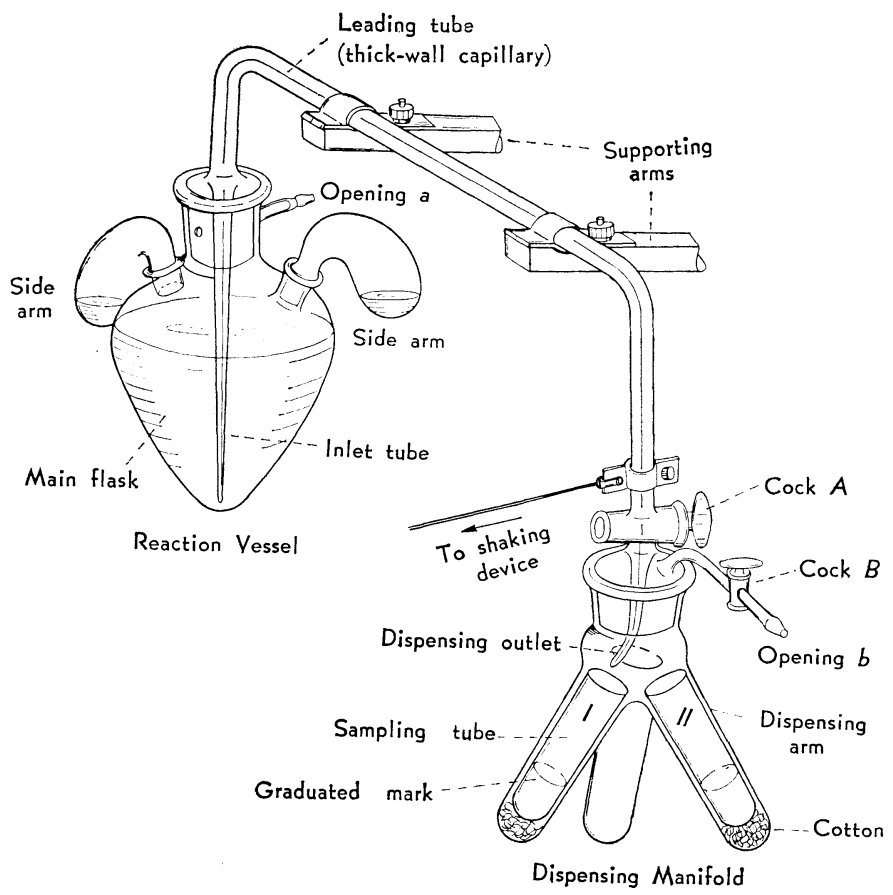

Fig. 1. Apparatus devised for sampling of a reaction mixture placed under atmosphere, in which a definite amount of gaseous radioactive substance can be introduced without diffusing off.

First, with cock $B$ opened and cock $A$ closed, the dispensing manifold is evacuated slightly with the aid of an aspirator through opening $b$, and then cock $B$ is closed. On opening cock $A$ carefully, the culture flushes into the sampling tube $I$ placed in the dispensing arm $I$. After flushing out a small amount of the culture which has been left in the leading tube, cock $A$ is closed and the dispensing manifold is turned to bring dispensing arm II under the opening of the dispensing outlet. Then cock $A$ is again opened until the sample in an amount slightly in excess of a desired volume (known by the graduation on the sampling tube) is obtained. After closing cock $A$ tightly, cock $B$ is opened, the dispensing manifold separated from the apparatus, and then from the sampling tube $I I$ an aliquot of desired amount is taken out. The two sampling tubes used are, after washing, reset in the apparatus for the next sampling.

The Warburg-flasks were used only when the sampling was carried out at the end of cultivation.

${ }^{14} \mathrm{CO}_{2}$-incorporation experiments. A solution of $\mathrm{Na}_{2}{ }^{14} \mathrm{CO}_{3}$ was used for the experiments. Aliquots of the culture were filtered by suction through a 
membrane filter (Membranfiltergesellschaft, Nr. 1) and subjected to necessary treatments. When the incorporation into whole cells was examined, the membrane filter on which conidia had been collected was attached on planchets and dried in a dessicator over phosphorus pentoxide. Other samples were dried carefully under an incandescent lamp.

Chemical analyses and radioactivity measurement. Chemical fractionation of cell samples was performed by the method of Schneider (6) using trifluoroacetic acid (TFA) instead of trichloroacetic acid as an extracting acid.

Hydrolysis of the nucleic acid fraction was carried out as follows. The hot-TFA extract of the conidia was evaporated in vacuo and hydrolyzed with TFA at $150^{\circ}$ for $80 \mathrm{~min}(\boldsymbol{7})$. The hydrolysate was evaporated in vacuo and dissolved in a small amount of water. The solution was treated with a resin, Duolite S-30, to remove brownish color, evaporated in vacuo, and then the residue subjected to paper chromatography.

Paper chromatography for the acid-soluble fraction and for the hydrolysate of nucleic acid was performed using solvent systems of butanol-acetic acidwater $(4: 1: 5)$ and isopropanol-HCl-water $(34: 8: 8)(8)$, respectively.

Radioactivity was measured using a gas-flow counter under the conditions ignoring self-absorption.

Fractionation into subcellular fractions of conidia. After the conidia were cultured for $45 \mathrm{~min}$ in a closed flask, the culture was flushed with air to expell remaining ${ }^{14} \mathrm{CO}_{2}$ which was absorbed in a $\mathrm{NaOH}$ solution. The germinating conidia were harvested by centrifugation, and washed with water until practically no radioactivity was found in the washing. The labeled conidia were then suspended in $0.01 \mathrm{~m}$ phosphate buffer $(\mathrm{pH} 7.0$ ) containing $0.01 \mathrm{~N} \mathrm{MgSO}_{4}$, and subjected to sonication for $15 \mathrm{~min}$ at $4^{\circ}$ in the presence of glass beads $(0.3 \mathrm{~mm}$ in average diameter). The sonicate was centrifuged at $800 \times g$ for $8 \mathrm{~min}$ to collect the cell debris, and the supernatant was centrifuged again at $105,000 \times g$ for $1 \mathrm{hr}$. Thus the supernatant and sediment were separated.

\section{RESULTS}

${ }^{14} \mathrm{CO}_{2}$-uptake by germinating conidia

When $A$. niger conidia were cultured in a germination medium supplemented with $\mathrm{Na}_{2}{ }^{14} \mathrm{CO}_{3}$, the radioactivity of the whole cells changed in a characteristic manner during germination (Fig. 2). The ${ }^{14} \mathrm{CO}_{2}$-incorporation took place without any appreciable lag and at the 3rd and 6.5th hr of incubation there occurred conspicuous falls in radioactivity of germinating conidia. The latter phenomenon may possibly be caused by the dilution effect of $\mathrm{CO}_{2}$ ("cold") evolved during the process of germination.

In the following experiments, the fate of ${ }^{14} \mathrm{CO}_{2}$ in the early phase of germination was examined. 


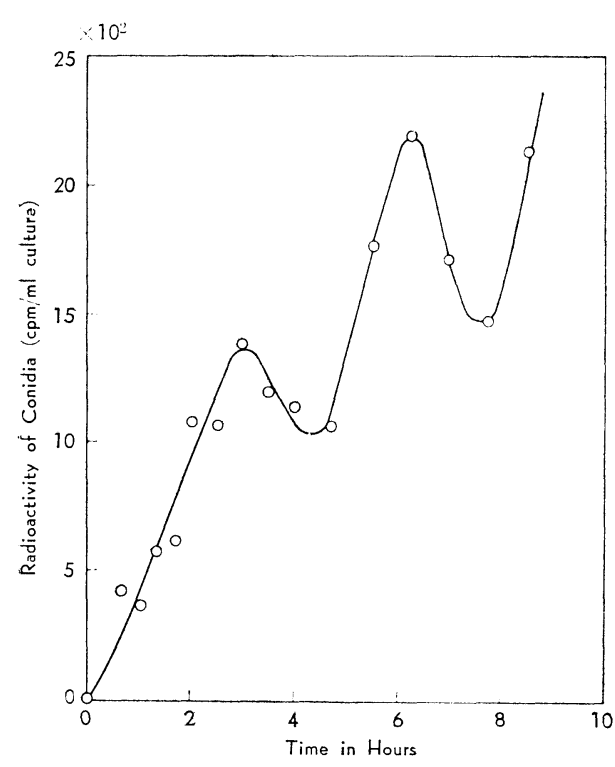

Fig. 2. Course of ${ }^{14} \mathrm{CO}_{2}$-incorporation into germinating conidia of Aspergillus niger.

Culture contained $1 \mu \mathrm{c} \mathrm{Na}{ }_{2}{ }^{14} \mathrm{CO}_{3}$ and $10 \mathrm{mg}$ conidia per $22 \mathrm{ml}$ medium.
Environmental factors affecting ${ }^{14} \mathrm{CO}_{2}$-uptake by conidia

As reported earlier by TAKEBE and Shimizu (9), the loss of heatresistance in $A$. niger conidia could be regarded as one of the criteria of germinaton as in the case of bacterial spore germination. They compared the viabilities after $3 \mathrm{~min}$ heating at $50^{\circ}$ of conidia which had been incubated for $1.5 \mathrm{hr}$ in various media. It was found that the death caused by the heating occurred most markedly in the conidia cultured in a complete medium and almost none in those incubated in water or in phosphate buffer. Appreciable death was observed when the conidia were cultured in alanine or glucose in the presence of phosphate (see Table 1).

With reference to these findings, the capacity to incorporate ${ }^{14} \mathrm{CO}_{2}$ in the conidia cultured for $45 \mathrm{~min}$ in various media was compared. As

Table 1. ${ }^{14} \mathrm{CO}_{2}$-uptake by Aspergillus niger conidia incubated in various media.

\begin{tabular}{l|c|c}
\multicolumn{1}{c|}{ Medium } & $\begin{array}{c}\text { Radioactivity } \\
\text { (cpm/ml culture })\end{array}$ & $\begin{array}{c}\text { Loss of heat- } \\
\text { resistance } \\
(\% \text { dead })\end{array}$ \\
\hline Complete ${ }^{o}$ & 16,000 & 94 \\
Water & 5,170 & 6 \\
Phosphate $(\mathrm{Ph})$ & 3,680 & 10 \\
Alanine $+\mathrm{Ph}$ & 9,930 & 73 \\
Proline $+\mathrm{Ph}$ & 7,370 & - \\
Guanine $+\mathrm{Ph}$ & 6,420 & - \\
Glucose $+\mathrm{Ph}$ & 10,680 & 87 \\
\hline
\end{tabular}

Each culture contained $2.5 \mu \mathrm{c} \quad \mathrm{Na}_{2}{ }^{14} \mathrm{CO}_{3}$ and $2.5 \mathrm{mg}$ conidia per 4.2 $\mathrm{ml}$ medium, and cultured in Warburg flasks for $45 \mathrm{~min}$ at $30^{\circ}$.

a Complete medium contained per liter: DL-alanine, $300 \mathrm{mg}$; Lproline, $200 \mathrm{mg}$; guanine, $10 \mathrm{mg}$; glucose, $10 \mathrm{~g} ; \mathrm{KH}_{2} \mathrm{PO}_{4}, 2.3 \mathrm{~g}$; and $\mathrm{Na}_{2} \mathrm{HPO}_{4} \cdot 12 \mathrm{H}_{2} \mathrm{O}, 1.8 \mathrm{~g}$ ( $\mathrm{pH}$ 6.0). All the other media used contained these substances in the same concentrations as described above.

$b$ From the data of TAKeBe and Shimizu (9). 
shown in Table 1, the highest activity was exhibited in the complete medium, whereas only a low but definite activity was demonstrated even in water or in phosphate buffer. Noteworthy was the finding that when the phosphate buffer was supplemented with alanine or glucose, the incorporation of ${ }^{14} \mathrm{CO}_{2}$ was strikingly enhanced and at the same time the loss of heat-resistance of conidia occurred at a high rate.

These observations indicated that the conidia possess the capacity for $\mathrm{CO}_{2}$-incorporation even in their state of dormancy, and that it increases considerably with the onset of germination.

Distribution of ${ }^{14} \mathrm{C}$ in cellular fractions extracted from germinating ${ }^{14} \mathrm{C}-$ labeled conidia

To examine whether there is any difference in the mode of ${ }^{14} \mathrm{CO}_{2}$-incorporation between the dormant and germinating conidia, the following experiment was carried out. The conidia cultured for $45 \mathrm{~min}$ in the complete medium and phosphate buffer, both supplemented with $\mathrm{Na}_{2}{ }^{14} \mathrm{CO}_{3}$, were fractionated by the method of Schneider (6) and the radioactivity of each fraction was measured.

The results summarized in Table 2 show that in the case of conid:a

Table 2. ${ }^{14} \mathrm{CO}_{2}$-incorporation into various fractions of Aspergillus niger conidia incubated under germinating and non-germinating conditions.

\begin{tabular}{l|c|c}
\multirow{2}{*}{ Fraction } & \multicolumn{2}{|c|}{ Radioactivity (cpm/ml culture) shown under } \\
\cline { 2 - 3 } & $\begin{array}{c}\text { Germinating condition } \\
\text { (complete medium })^{\circ}\end{array}$ & $\begin{array}{c}\text { Non-germinating condition } \\
\text { (phosphate buffer) }\end{array}$ \\
\hline Whole conidia & $14,650(100)^{\circ}$ & $5,050(100)^{b}$ \\
Acid-soluble & $5,800(39.7)$ & $3,210(63.5)$ \\
Lipid & $202(1.4)$ & $70(1.4)$ \\
Nucleic acids & $1,488(10.1)$ & $372(7.4)$ \\
Residual & $6,050(41.5)$ & $765(15.1)$ \\
\hline
\end{tabular}

Each lot, incubated in Warburg vessels for $45 \mathrm{~min}$ at $30^{\circ}$, contained $2.5 \mu \mathrm{c} \mathrm{Na}_{2}{ }^{14} \mathrm{CO}_{3}$ and $2.5 \mathrm{mg}$ conidia per $4.3 \mathrm{ml}$ medium. Fractionation was carried out by the method of SCHNEIDER $(6)$.

${ }^{a}$ For the composition see Table 1 .

$\checkmark$ Numbers in parentheses represent percentages of radioactivity referred to those of whole conidia. In both cases the total sum of the counts found for all fractions was less than that of whole conidia. This might probably be caused by the loss of volatile substances in the acid-soluble fraction during drying.

cultured in the complete medium, the highest radioactivity was in the residual fraction (containing protein and polysaccharide) and in the acid-soluble fraction followed by that in the nucleic acid fraction. In comparison, the conidia incubated in the phosphate buffer gave the highest radioactivity in 
the acid-soluble fraction. These results suggest that in the dormant stage $\mathrm{CO}_{2}$ is incorporated mostly in substances of smaller molecules appearing in the acid-soluble fraction, and that with the onset of germination an active incorporation into macromolecules, presumably from those in the acidsoluble fraction, takes place.

Analysis of the acid-soluble fraction obtained from the conidia germinating in the complete medium gave the result reproduced in Fig 3. The paper chromatogram of the untreated acid-soluble fraction showed the highest radioactivity close to the original point of application, whereas that of the same

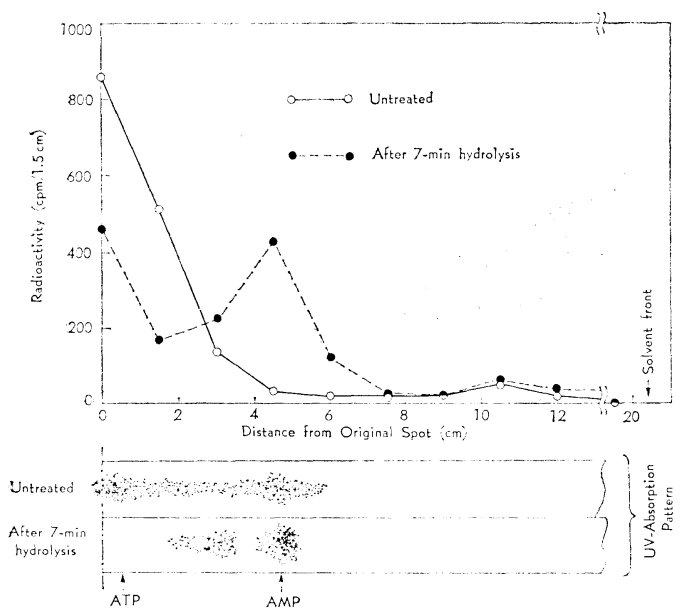

Fig. 3. Paper chromatogram of the acid-soluble fraction extracted from the conidia that were induced to germinate by being incubated for $45 \mathrm{~min}$ in complete medium supplemented with $\mathrm{Na}_{2}{ }^{14} \mathrm{CO}_{3}$. Solvent system used was butanol-acetic acid-water $(4: 1: 5)$.

Upper graph shows scanning diagrams of the paper obtained for the untreated and hydrolyzed samples of the fraction. Lower figure shows UVabsorption patterns of these samples. Arrows indicate the location of AMP and ATP shown by respective reference standards. with TFA (7) and the hydrolysates were subjected to paper chromatography. Fig. 4 shows the autoradiograms obtained, in which the autoradiographic patterns coincided with five ultraviolet-absorbing spots. Of these spots the strongest were those corresponding to adenine, cytosine and uridine and the weakest were those corresponding to guanine and thymine, the latter of which was, however, recognizable even in the conidia incubated only for $15 \mathrm{~min}$ 
under the germinating condition. It is rather astonishing that the $\mathrm{CO}_{2}$-incorporation into DNA takes place in such an early phase of germination.

${ }^{14} \mathrm{C}$-incorporation into subcellular fractions of germinating conidia labeled with ${ }^{14} \mathrm{CO}_{2}$

Chemical fractionation of germinating conidia labeled with ${ }^{14} \mathrm{CO}_{2}$ showed that a high radioactivity appeared in the residual fraction which was supposed to be composed mainly of protein and cell wall polysaccharide. To clarify the nature of the macromolecules which incorporate ${ }^{14} \mathrm{CO}_{2}$ in the early phase of germination, the conidia cultured for $45 \mathrm{~min}$ in the presence of $\mathrm{Na}_{2}{ }^{14} \mathrm{CO}_{3}$ were disintegrated by sonication and subjected to differential centrifugation. The results presented in Table 3 clearly show that the radioactivity was exceedingly high in the supernatant and only slight in the cell debris $(800 \times g$ pellets). This suggests that the labeling of conidia with ${ }^{14} \mathrm{CO}_{2}$ in the early phase of germination occurred mostly in soluble protein and nucleic acids and only slightly, if any, in cell wall polysaccharide.

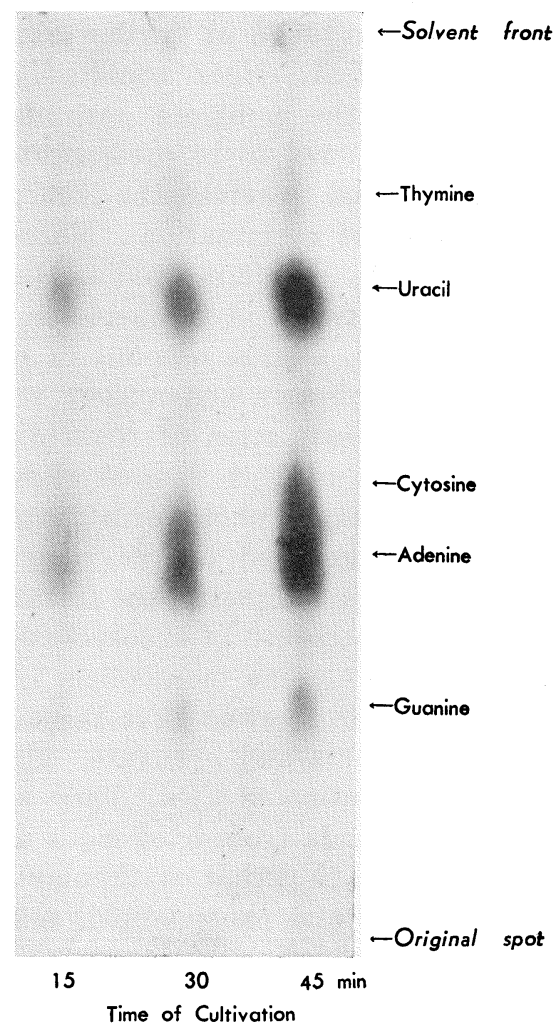

Fig. 4. Autoradiogram of the hydrolysate of nucleic acids extracted from ${ }^{14} \mathrm{C}$ labeled germinating conidia of Aspergillus niger.

For experimental details see text.

Table 3. ${ }^{14} \mathrm{CO}_{2}$-incorporation into subcellular fractions obtained from germinating conidia.

\begin{tabular}{c|c}
\hline Subcellular fraction & $\begin{array}{c}\text { Radioactivity } \\
(\mathrm{cpm} / \mathrm{ml} \text { culture })\end{array}$ \\
\hline $800 \times g$ pellets & 408 \\
$105,000 \times g$ pellets & 972 \\
$105,000 \times g$ supernatant & 5,620 \\
\hline
\end{tabular}

Test mixture contained $25 \mathrm{mg}$ conidia and $10 \mu \mathrm{c} \mathrm{Na}{ }_{2}{ }^{14} \mathrm{CO}_{3}$ in 50 ml medium (complete).

\section{DISCUSSION}

Our observation that ${ }^{14} \mathrm{CO}_{2}$ was incorporated actively into germinating 
conidia may be taken as further evidence for the essentiality of $\mathrm{CO}_{2}$ in the germination of $A$. niger conidia(1). Among various substrates which are necessary for the complete germination, ${ }^{32} \mathrm{P}$-phosphate, ${ }^{35} \mathrm{~S}$-sulfate and ${ }^{14} \mathrm{C}-$ alanine were found to be incorporated into conidia after more or less appreciable lag period, whereas the incorporation of ${ }^{14} \mathrm{CO}_{2}$ occurs without any lag at the start of germination. Moreover, it was revealed that ${ }^{14} \mathrm{CO}_{2}$ is incorporated even by dormant conidia. In this case, however, most of the incorporated ${ }^{14} \mathrm{C}$ was found in the acid-soluble fraction, whereas in the early phase of germination, a large amount of incorporated ${ }^{14} \mathrm{C}$ was found in macromolecules such as protein and nucleic acids.

Earlier investigation of NisHI (4) on the phosphorus metabolism of germinating conidia of this fungus showed that polyphosphate and phospholipids serve as suppliers of phosphorus for the formation of ATP which is the major intermediate produced in the early phase of germination. The present investigation also suggested the formation of ATP in the early phase of germination at the expense of incorporated $\mathrm{CO}_{2}$. Studies carried out by Hoshino et $a l$. (10) on the alanine metabolism in the early phase of germination of this fungal conidium showed that the alanine taken up was instantly deaminated to give ammonia and pyruvate, which in turn was decarboxylated gradually with the formation of $\mathrm{CO}_{2}$. They also found the formation of glycine and other amino acids from exogenous alanine in the germinating conidia. Thus, exogenous $\mathrm{CO}_{2}$ together with alanine and endogenous phosphorus reserves (polyphosphate and phospholipid) serve as materials for the ATP formation at the initial stage of conidia germination.

An important finding in the present study was that ${ }^{14} \mathrm{CO}_{2}$ was definitely incorporated into nucleic acids (RNA and DNA) immediately at the onset of germination. Analysis of bases showed that adenine, cytosine and uridine were strongly labeled, while thymine was less strongly, but definitely labeled. Such a pattern of labeling with ${ }^{14} \mathrm{CO}_{2}$ was quite similar to that of labeling observed in the ${ }^{14} \mathrm{C}$-alanine-feeding experiment (10). We also found that the base composition of RNA contained in conidia changed in a characteristic manner before and after germination. The ratio of purine to pyrimidine of RNA extracted from dormant and germinating conidia were 1.20 and 1.05 , respectively(10). The labeling pattern of nucleic acids (Fig. 4) with either ${ }^{14} \mathrm{CO}_{2}$ or ${ }^{14} \mathrm{C}$-alanine may well explain such a change in the purine to pyrimidine ratio of RNA. These observations imply that some modification or reconstruction of nucleic acids occurs during the early phase of conidia germination. It may also be inferred that the pyrimidine nucleotides in the nucleic acids could be synthesized from materials of exogenous and endogenous origins as discussed above; ammonia being derived from alanine, $\mathrm{CO}_{2}$, phosphorus reserves, and aspartate(11) may serve as building blocks.

\section{SUMMARY}

Incorporation of ${ }^{14} \mathrm{CO}_{2}$ into conidiospores of Aspergillus niger (strain 1617) 
was investigated under various cultural conditions.

The conidia incubated in a complete germination medium incorporated ${ }^{14} \mathrm{CO}_{2}$ very actively without any lag period. By using various media for incubation, it was found that the more favorable the medium for the germination, the more active was the ${ }^{14} \mathrm{CO}_{2}$-incorporation. In the germinating conidia fed with ${ }^{14} \mathrm{CO}_{2}$, a large amount of radioactivity was found in the protein fraction as well as in the acid-soluble fraction, in which ATP was revealed to be one of the major substances to be labeled within a short period. Quickly labeled were also nucleic acids, in which adenine, cytosine and uracil were strongly labeled, while thymine and guanine were less strongly, but definitely, labeled even at the onset of germination.

Based on these observations as well as those made earlier of the phosphorus and alanine metabolisms of germinating conidia, inferences and discussions were made of the biochemical events occurring in the early phase of conidia germination.

\section{REFERENCES}

(1) T. Yanagita: Arch. Mikrobiol., 26, 329 (1957).

(2) A. RiPPel and H. Bortels: Biochem. Z., 184, 237 (1927).

(3) T. Yanagita and S. Yamagishi: Appl. Microbiol., 6, 375 (1958).

(4) A. Nishi: J. Bacteriol., 81, 10 (1961).

(5) T. Yanagita and A. Nishi: Ann. Rept. Inst. Food Microbiol., Chiba Univ., 12, 40 (1959).

(6) W. C. Schneider: J. Biol. Chem., 161, 293 (1945).

( 7 ) S. K. Dutta, A. S. Jones and M. Stacy: J. Gen. Microbiol., 14, 160 (1956).

(8) G. R. WYATT: Biochem. J., 48, 584 (1951).

(9) I. TAKebe and N. Shimizu: Ann. Rept. Inst. Food Microbiol., Chiba Univ., 12, 29 (1959).

(10) J. Hoshino, A. Nishi and T. Yanagita: J. Gen. Appl. Microbiol., 8, 233 (1962).

(11) I. Takebe and T. Yanagita: Plant \& Cell Physiol., 1, 17 (1959). 